\title{
Antimicrobial use of reactive oxygen therapy: current insights
}

This article was published in the following Dove Press journal: Infection and Drug Resistance

\author{
Mohammad Yousef Memar' \\ Reza Ghotaslou' \\ Mohammad Samiei ${ }^{3}$ \\ Khosro Adibkia ${ }^{4}$ \\ 'Immunology Research Center, \\ Tabriz University of Medical \\ Sciences, Tabriz, Iran; ${ }^{2}$ Department \\ of Microbiology, School of Medicine, \\ Tabriz University of Medical Sciences, \\ Tabriz, Iran; ${ }^{3}$ Faculity of Dentistry, \\ Tabriz University of Medical Sciences, \\ Tabriz, Iran; ${ }^{4}$ Research Center for \\ Pharmaceutical Nanotechnology and \\ Faculty of Pharmacy, Tabriz University \\ of Medical Sciences, Tabriz, Iran
}

\begin{abstract}
Infections caused by drug-resistant pathogens are a global public health problem. The introduction of a new antimicrobial strategy is an unavoidable option for the management of drug-resistant pathogens. Induction of high levels of reactive oxygen species (ROS) by several procedures has been extensively studied for the treatment of infections. In this article, the general aspects of ROS production and the common procedures that exert their antimicrobial effects due to ROS formation are reviewed. ROS generation is the antimicrobial mechanism of nanoparticles, hyperbaric oxygen therapy, medical honey, and photodynamic therapy. In addition, it is an alternative bactericidal mechanism of clinically traditional antibiotics. The development of ROS delivery methods with a desirable selectivity for pathogens without side effects for the host tissue may be a promising approach for the treatment of infections, especially those caused by drug-resistant organisms.
\end{abstract}

Keywords: antibiotic resistance, infections, reactive oxygen species

\section{Introduction}

The outbreaks of infections caused by antibiotic-resistant microbial pathogens are costly and may possibly become lethal. The emergence and outbreaks of antibioticresistant bacteria are a worldwide hazard to both humans and animals and are commonly uncontrollable. ${ }^{1,2}$ The discovery of antimicrobial agents is not a routine procedure, and resistance has developed to most antibiotics, regardless of their chemical characteristics or molecular targets. ${ }^{3}$ The management of the global challenge of antimicrobial resistance needs a decrease in antibiotic administration to decrease the choice pressure, an efficient infection control strategy to reduce the spread of resistant organisms, and novel antimicrobial drugs. ${ }^{4} \mathrm{New}$ agents to reach clinical practice are reactive oxygen species (ROS), which have antimicrobial activity. ROS have an effective antimicrobial action against a wide spectrum of pathogens. ROS are effective in vitro against most Gram-positive and Gram-negative organisms, including multidrug-resistant isolates which are causing infection control and therapeutic problems. ${ }^{5}$ The term "ROS" refers to reactive radicals, including superoxide anion $\left(\mathrm{O}_{2}^{-}\right)$, singlet oxygen $\left(\mathrm{O}_{1}^{2}\right)$, peroxide $\left(\mathrm{O}_{2}^{-2}\right)$, hydrogen peroxide $\left(\mathrm{H}_{2} \mathrm{O}_{2}\right)$, hydroxyl radicals $\left(\mathrm{OH}^{-}\right)$, and hydroxyl $\left(\mathrm{OH}^{-}\right)$ions that are constantly harvested as side products of some cell biologic process. ${ }^{5,6}$ The use of ROS is a new therapeutic approach for topical use on skin, mucosal membranes, or internal tissue that may be colonized with microbial inhabitants and biofilms. ${ }^{7}$ This study presents an overview of ROS formation and the use of ROS-dependent procedures for antimicrobial therapy.
Correspondence: Khosro Adibkia Faculty of Pharmacy, Tabriz University of Medical Sciences, Golgasht Street, Daneshgah Avenue, Tabriz, Iran Tel +984133341315

Fax +98 4I 33344798

Email adibkia@tbzmed.ac.ir 


\section{ROS generation and the enzymes used for scavenging}

Molecular oxygen $\left(\mathrm{O}_{2}\right)$ is used by aerobic organisms for respiration and for the oxidation of metabolites to acquire energy. ${ }^{8}$ It is a nonpolar small molecule that diffuses quickly across typical biologic membranes through water. ${ }^{9}$ After entering the microbes, environmental $\mathrm{O}_{2}$ interacts with the cellular structure and uses it for adenosine triphosphate generation during the process of oxidative phosphorylation. This process is associated with the reduction process of $\mathrm{O}_{2}$ to water, and it is the central mechanism providing energy to aerobic organisms. ${ }^{10}$ The interactions between $\mathrm{O}_{2}$ and biologic molecules, especially respiratory flavoenzymes, are associated with ROS formation (Figure 1). Flavoenzymes are catalytic redox cofactors that readily transfer e to $\mathrm{O}_{2}$. Intracellular ROS, including superoxide $\left(\mathrm{O}_{2}{ }^{--}\right), \mathrm{H}_{2} \mathrm{O}_{2}$, and highly destructive hydroxyl radicals ( $(\mathrm{OH})$, are generated by successive single-electron reductions. ${ }^{11}$ Both $\mathrm{O}_{2}{ }^{--}$and $\mathrm{H}_{2} \mathrm{O}_{2}$ can be produced in this pathway. Some studies have reported that the related levels of $\left(\mathrm{O}_{2}{ }^{--}\right)$are produced by the respiratory chain, but not $\mathrm{H}_{2} \mathrm{O}_{2}$. The detailed biologic mechanism of high-level $\mathrm{H}_{2} \mathrm{O}_{2}$ formation during the stable state is not well described. ${ }^{11,12}$ Several studies have reported evidence for the involvement of the ROS produced as a promoting agent in mutagenesis and as a causative agent of the mutational events influencing the microbes during oxidative stress. This theory is supported by the presence of a certain cellular enzymatic pathway in microorganisms that detoxifies $\mathrm{ROS}$. $\mathrm{OH}^{\bullet}$ is produced in vivo during the Fenton reaction, in which $\mathrm{H}_{2} \mathrm{O}_{2}$ is oxidized with the available ferrous iron $\left(\mathrm{Fe}^{2+}\right)$ to generate $\mathrm{OH}^{\bullet}$ $\left(\mathrm{H}_{2} \mathrm{O}_{2}+\mathrm{Fe}^{2+} \rightarrow \mathrm{OH}^{\bullet}+\mathrm{OH}^{-}+\mathrm{Fe}^{3+}\right)$. This reaction is dependent on

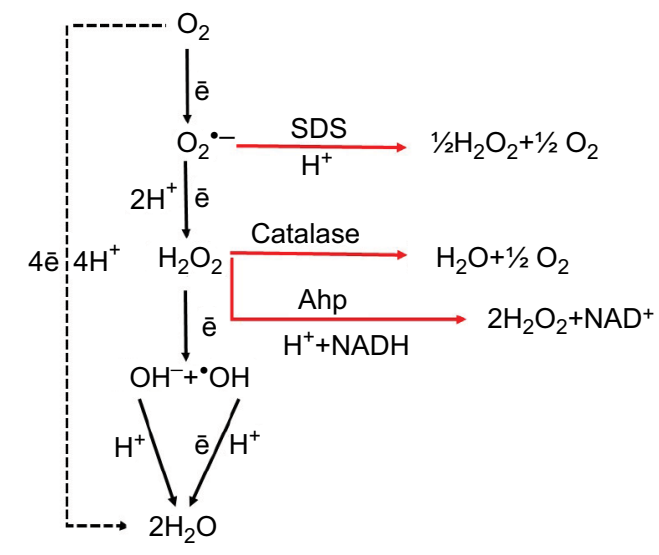

Figure I ROS formation and scavenging.

Notes: Consecutive addition of $\overline{\mathrm{e}}$ and $\mathrm{O}_{2}$ is associated with the ROS formation. $\mathrm{O}_{2}^{--}$is inactivated enzymatically by SOD. catalase scavenge $\mathrm{H}_{2} \mathrm{O}_{2}$.

Abbreviations: Ahp, alkyl hydroperoxide reductase; ROS, reactive oxygen species; SOD, superoxide dismutase. the Haber-Weiss reaction, through which $\mathrm{O}_{2}{ }^{--}$reduces ferric iron $\left(\mathrm{Fe}^{3+}\right)$ to generate $\mathrm{Fe}^{2+} . \mathrm{O}_{2}{ }^{-}$can interact with free independent $\mathrm{Fe}^{3+}$, or it may destabilize and/or release Fenton-ready $\mathrm{Fe}^{2+}$ due to a reductive reaction with iron-sulfur-containing enzymes. Reduction of $\mathrm{O}_{2}^{--}$and $\mathrm{H}_{2} \mathrm{O}_{2}$ can be catalyzed by

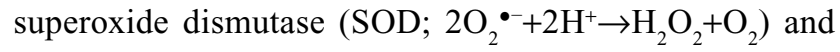
catalases/peroxidases $\left(2 \mathrm{H}_{2} \mathrm{O}_{2} \rightarrow 2 \mathrm{H}_{2} \mathrm{O}+\mathrm{O}_{2}\right)$, respectively (Figure 1). Enzymatic cellular elimination of $\mathrm{OH}^{\cdot}$ and ${ }^{1} \mathrm{O}_{2}$ has not been described so far. Therefore, the nonselective oxidative interactions of $\mathrm{OH}^{\cdot}$ and ${ }^{1} \mathrm{O}_{2}$ with biologic molecules may have destructive and lethal effects.

\section{Oxidative stress in bacteria}

ROS are constantly generated as secondary metabolites of some biologic processes and from certain cell procedures under delicate control. Simultaneously, reactions involving ROS are catalyzed by some specific or nonspecific reactions. Two dissimilar procedures, the production and the elimination of ROS, are normally controlled by fine cellular mechanisms, and the stable level of ROS are present in the cells. ${ }^{13}$ However, under certain conditions, the equilibrium between ROS generation and degradation is disturbed as a result of their increased concentration, referred to as oxidative stress. ${ }^{14}$ Under these circumstances and under normal conditions, the free radicals produced can change all types of biologic molecules that, if not taken up, accumulate in the cell. ${ }^{10}$ Several chemical and physical factors can lead to increase in ROS levels to a threshold that exceeds the cellular tolerance and, thereby, oxidative stress. Certain immune cells also stimulate oxidative stress by expressing NADPH oxidase and myeloperoxidase, upon the phagocytosis of invasive bacteria, as a defense mechanism. ${ }^{8}$ Heat shock, ionizing radiation, and ultraviolet radiation induce the generation of extremely injurious free radicals due to different mechanisms that cause oxidative stress. ${ }^{15,16}$ Oxidative stress is involved in the antibacterial mechanisms of some antibiotics such as quinolones, $\beta$-lactams, and aminoglycosides that motivate $\mathrm{OH}^{\bullet}$ generation through the Fenton reaction. ${ }^{17,18}$ Engineered nanoparticles induce oxidative stress in cells by producing reactive radicals at or near their surface. ${ }^{19,20}$

\section{The biologic targets of ROS}

During oxidative stress, the $\mathrm{O}_{2}{ }^{--}$formed at the cellular membrane by the respiratory chain is catalyzed by SOD to $\mathrm{H}_{2} \mathrm{O}_{2}$ and it reduces $\mathrm{Fe}^{3+}$ through the Haber-Weiss reaction. $\mathrm{H}_{2} \mathrm{O}_{2}$ can then oxidize $\mathrm{Fe}^{2+}$ by the Fenton reaction to produce $\mathrm{OH}^{\bullet}$ and $\mathrm{Fe}^{3+}$, thus possibly beginning an injurious redox sequence of ROS attack and formation. Since $\mathrm{Fe}^{2+}$ is capable of binding 
to biomolecules, $\mathrm{OH}^{\bullet}$ formation can occur in the DNA, proteins, and lipids in the immediate vicinity, thereby causing its damaging effect. $\mathrm{Fe}^{2+}$ shows a sequence-specific affinity when interacting with DNA and contributing to the Fenton reaction. The cellular targets for the toxic effects of ROS are DNA, RNA, proteins, and lipids. ${ }^{21}$ Most of the destruction is triggered by the $\mathrm{OH}$ produced by the Fenton reaction, which needs iron (or an alternative divalent metal ion) and reducing agent (such as NADH). A reducing agent is essential for reproduction of iron or alternative divalent metal ion. ${ }^{8}$ The antimicrobial effects of ROS are directly prompted by interaction with the thiol groups in proteins, DNA, and cell membranes through a dose-dependent effect. ${ }^{4}$ DNA is the main target in $\mathrm{H}_{2} \mathrm{O}_{2}$-dependent cytotoxicity in an interaction that affects the bases of DNA or damages it by breaking up the deoxyribose structure. ROS induce physical destruction in incorporated or free nucleotides; in addition, they break single- or double-stranded DNA in the double helix. Moreover, DNA can be broken by the by-products of lipid peroxidation. ${ }^{22,23}$ The RGGG sequences and RTGR sites are the most nicked at $10-50$ and $0.05-2.5 \mathrm{mM}_{\text {of }} \mathrm{H}_{2} \mathrm{O}_{2}$, respectively. ${ }^{24}$ The effect at lower levels of $\mathrm{H}_{2} \mathrm{O}_{2}$ is represented as Mode I, while that at higher $\mathrm{H}_{2} \mathrm{O}_{2}$ levels is denoted as Mode II. ${ }^{25}$ ROS or free radicals induce direct damage to lipids at high concentrations. The destructive $\mathrm{OH}^{\bullet}$ can promote the peroxidation of lipids and can trigger the chain oxidation of polyunsaturated phospholipids of the cell membranes, consequently resulting in their reduced functions. ${ }^{26}$ Damage induced by ROS to the bacterial cell membrane differs from that caused to eukaryotes because of the absence of polyunsaturated phospholipids in the membrane of most prokaryotes. ${ }^{27}$ Peroxidation of lipids has been demonstrated after phagocytosis of bacteria by the neutrophils, but it is not recognized whether it is associated with or induces bacterial killing. ${ }^{28}$ ROS can cause disruption in the membrane lipid bilayer organization that may deactivate membrane-located receptors and proteins, eventually leading to cell fluidity, efflux of cytosolic contents, and the defeat of membrane-functions. ${ }^{27,29}$ Proteins are also a main biologic target of ROS. Different types of damage are recognized, such as oxidation of sulfhydryl groups, reduction of disulfides, oxidative adduction of amino acid residues near to metal-binding locations through metal-dependent oxidation, interaction with aldehydes, alteration of prosthetic groups or metal clusters, protein-protein cross-linking, and peptide breakup. ${ }^{8}$ Proteins can be subjected to a variety of specific oxidative alterations at cysteine, methionine, tyrosine, phenylalanine, and tryptophan residues. Protein carbonyls that are generated by the oxidative reaction of arginine, proline, or lysine are detectable following oxidative damage. $\mathrm{H}_{2} \mathrm{O}_{2}$ can cause oxidative modifications in proteins, such as elongation factor $\mathrm{G}$, DnaK, alcohol dehydrogenase E, enolase, OppA, OmpA, and the F0F1-ATPase of Escherichia coli. ${ }^{28,30}$

\section{Cellular defense mechanisms against ROS}

The cellar defenses against ROS can be summarized into three chief mechanisms: 1) suspension of ROS formation; 2) suppression of chain propagation; and 3) repair of damage. ${ }^{10}$ Due to their simplicity compared to eukaryotes, prokaryotes have been generally used as a model to investigate and describe the processes of ROS generation and oxidative stress effects on cells. ${ }^{31}$ E. coli produces SOD and catalase, which actualize $\mathrm{O}^{--}$and $\mathrm{H}_{2} \mathrm{O}_{2}$, respectively, as a response to oxidative stress. Unlike mammalians that use only two types of SOD, E. coli has three SOD isoforms (MnSOD [sodA], FeSOD [sodB], and CuZnSOD [sodC]) that contain different metal cationic cores. E. coli also has two types of catalase (hydroperoxidase I and hydroperoxidase II). OxyR and SoxRS are oxidative stress regulators that transcriptionally regulate catalases and SOD in response to $\mathrm{H}_{2} \mathrm{O}_{2}$ and $\mathrm{O}^{--}$, respectively, in E. coli. ${ }^{31,32}$ Several bacterial pathogens prevent the increase of ROS by directly inhibiting the synthesis of NADPH oxidase. In these cases, organisms generally inhibit the recruitment of critical subunits to the phagosome or NADPH oxidase, thus decreasing the induction of oxidative stress conditions in neutrophils. ${ }^{33-35}$

\section{The OxyR and the SoxRS systems}

When bacteria are exposed to high levels of $\mathrm{H}_{2} \mathrm{O}_{2}$, oxidative stress may occur. This condition is identified as a transcription factor referred to as OxyR, which responds rapidly to $\mathrm{H}_{2} \mathrm{O}_{2}$ through an active site containing a conserved cysteine residue. It is typically inactive during aerobic conditions when the cellular concentration of $\mathrm{H}_{2} \mathrm{O}_{2}$ is $\sim 50 \mathrm{nM}$. However, a cellular level of $\sim 200 \mathrm{nM} \mathrm{H} \mathrm{O}_{2}$ is adequate to stimulate OxyR into a disulfide-bonded type that actively induces the expression of a dozen operons around the chromosome. OxyR exists in oxidized or reduced forms which bind to DNA at different specific binding sites. This different specific binding to DNA allows OxyR to activate under different cellular circumstances. During oxidative stress, OxyR increases the expression of $k a t G$ and $a h p C$ genes by inducing the binding of RNA polymerase to the promoter. ${ }^{36}$

OxyR stimulates the production of catalase $\mathrm{G}$ and alkyl hydroxyperoxide reductase up to 10-fold to decrease $\mathrm{H}_{2} \mathrm{O}_{2}$ levels to safe concentrations. Other components of this 
regulator are well described in the aspect of destruction due to $\mathrm{H}_{2} \mathrm{O}_{2}$ generation and their roles in the resistance to $\mathrm{H}_{2} \mathrm{O}_{2}$. A different sensing and responding pathway to $\mathrm{H}_{2} \mathrm{O}_{2}$ demonstrated in some Gram-positive bacteria is controlled by the PerR repressor. Upon increase in $\mathrm{H}_{2} \mathrm{O}_{2}$ levels, the PerR protein is inactivated due to oxidation of its prosthetic iron. ${ }^{37}$ PerR controls many of the same homologous genes' enzymes that OxyR controls. ${ }^{38}$ The details of the $\mathrm{H}_{2} \mathrm{O}_{2}$-sensing mechanisms of this distinct regulation are unknown. ${ }^{9,39}$ In contrast to $\mathrm{H}_{2} \mathrm{O}_{2}, \mathrm{O}_{2}^{-}$is a charged molecule at normal $\mathrm{pH}$ and it cannot traverse the cell membranes. SoxR is another system that responds primarily to $\mathrm{O}_{2}{ }^{-}$under conditions of oxidative stress. ${ }^{40}$ SoxR contains a $2 \mathrm{Fe}-2 \mathrm{~S}$ cluster, which is oxidized under oxidative stress and activates SoxR. Activated SoxR stimulates the production of SoxS, which then motivates the expression of its target gene. These genes may be involved in eliminating oxidative agents, repairing systems of affected biomolecules and maintaining normal cellular physiologic circumstances. ${ }^{41,42}$

\section{ROS formation induced by metal nanoparticles}

The application of nanomaterials in clinical microbiology has gained significant attention in the field of chemotherapy because of their direct antimicrobial effects or as delivery systems. ${ }^{43-46}$ Potential antibacterial properties of some nanomaterials such as carbon nanotubes and metal-oxide nanoparticles (such as $\mathrm{Ag}$, silver oxide [ $\left.\mathrm{Ag}_{2} \mathrm{O}\right]$, titanium dioxide $\left[\mathrm{TiO}_{2}\right]$, silicon [Si], copper oxide $[\mathrm{CuO}]$, zinc oxide $[\mathrm{ZnO}], \mathrm{Au}$, calcium oxide $[\mathrm{CaO}]$, and magnesium oxide $[\mathrm{MgO}]$ ) have been extensively reported against both Gram-positive and Gram-negative bacteria. ${ }^{47-51}$ Oxidative stress due to ROS formation is the chief mechanism of the antibacterial affectivity. ${ }^{19,51,52}$ The potential of ROS production due to conversion of hydrogen peroxide by a Fentonlike pathway was described for metal nanoparticles. ${ }^{53,54}$ A multifunctional nanoparticle system was demonstrated for the simultaneous inhibition of catalase and induction of ROS production. ${ }^{55}$ This system can increase the sensitivity of biologic targets to the lethal effects of ROS. The toxic effects of different nanomaterials mediated by the formation of ROS have been reported in several biologic models, including human skin fibroblasts, erythrocytes, macrophages, keratinocytes, and monocytes. ${ }^{56}$ Engineered nanomaterials possess a small size, high specific surface area, and high surface reactivity, leading to the production of higher levels of ROS and resulting in cytotoxicity and genotoxicity. ${ }^{56,57}$ The photogeneration of ROS on the surfaces of metal-oxide nanoparticles has been investigated in several studies. ${ }^{36,51,58}$ The general principle of photogeneration is the absorption of a light having equivalent or greater energy than the band gap which prompts the electrons $\left(\mathrm{e}^{-}\right)$of the nanoparticles. The transfer of exited $\mathrm{e}^{-}$across the band gap to the conduction band creates a hole $\left(\mathrm{h}^{+}\right)$in the valence band that exhibits significant oxidizing activity. ${ }^{51}$ The interaction between molecular $\mathrm{O}_{2}$ and these electrons can induce $\mathrm{O}_{2}{ }^{--}$formation through a reduction reaction. ${ }^{51}$ The hole can prompt electrons from hydroxyl ions and/or water to $\mathrm{OH}$ formation due to an oxidative reaction. ${ }^{59}$ Quantitative differences of ROS induced by the same nanomaterial are due to the differences in characters of the nanoparticles (e.g., sources, synthetic techniques, size, shape, and concentration) and experimental settings (e.g., ionic power and $\mathrm{pH}$ of the solution and use of light illumination). ${ }^{51}$

\section{ROS formation induced by antibiotics}

Several corresponding studies have reported that ROS production and oxidative stress are associated with the drug lethality of some antimicrobial agents. ROS have been involved in antibiotic-mediated lethality, but the causal mechanisms of this influence remain uncertain. Recently, it has been reported that major groups of bactericidal agents, regardless of their drug-target interactions, prompt a common oxidative destruction of cellular targets in organisms, primarily by creating toxic ROS through the interference of the tricarboxylic acid pathway and the electron transport chain. ${ }^{60-62}$ Several bactericidal agents, such as $\beta$-lactams, quinolones, and aminoglycosides, can induce ROS generation, which are highly damaging molecules that can inhibit most functions of oxygen-respiring cells (Figure 2). ${ }^{63}$ The general process of toxic $\mathrm{OH}^{\cdot}$ generation involves the tricarboxylic acid pathway and a transient depletion of NADH, as well as iron-sulfur cluster instability and disturbance of iron regulation. ${ }^{11}$ Production of high levels of $\mathrm{OH}^{\cdot}$ may be the common mechanism for antimicrobial-mediated lethality. ${ }^{64}$ Antimicrobial agents enhance the generation of $\mathrm{O}_{2}^{-}$, which then enzymatically converts to peroxide, from which an extremely damaging ${ }^{\circ} \mathrm{OH}$ is produced. Then, ${ }^{\circ} \mathrm{OH}$ increases the bactericidal effects. ${ }^{64}$ The bactericidal effects of antimicrobial agents are decreased under strict anaerobic environments, but they could be increased by the addition of $\mathrm{O}_{2}$ or by exposure to another electron receptor, demonstrating that the environmental condition is a remarkable factor in the efficiency of antimicrobial agents. The overproduction of catalase or DNA repair system enzymes, MutS (a DNA 
mismatch repair protein), and the pre-exposure to antioxidants restrict antibiotic bactericidal effects, suggesting that ROS may play a critical role in antimicrobial agent lethality. ${ }^{65}$ The absence of $\operatorname{sod} A$ or $\operatorname{sod} B$ had no significant influence on norfloxacin's bactericidal effects; however, the deficiency of both genes together limited the killing effects, which was dependent on a quick conversion of inordinate levels of $\mathrm{O}_{2}^{-}$ to $\mathrm{H}_{2} \mathrm{O}_{2}$, contributing to the quinolone bactericidal effects. Norfloxacin is more effective with the mutant absence of $k a t G$

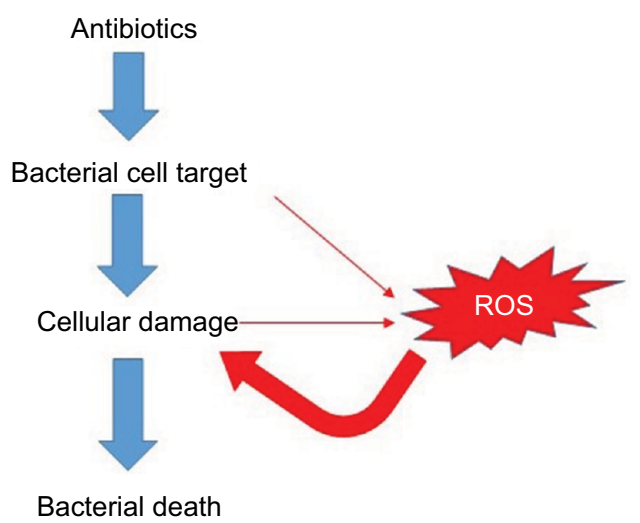

Figure 2 ROS induction by antibiotics.

Notes: Bactericidal antimicrobial agents by interacting with cellular specific targets induce the lethal cellular effect. In addition to special mechanisms, they induce the stress pathway that triggers redox-related condition. These conditions are associated with production of toxic reactive species, such as ROS, which induce cellular toxicity and lethal effects.

Abbreviation: ROS, reactive oxygen species. than with its isogenic source, indicating that detoxification of peroxide to water typically decreases quinolone efficiency. ${ }^{64}$

\section{Photodynamic therapy (PDT)}

PDT is a method based on ROS generation to cause the inactivation of eukaryote or prokaryote cells using a nontoxic dye known as the photosensitizer (PS) molecule in the presence of low strength visible light. ${ }^{66,67}$ The photodynamic inactivation of organisms is based on the idea that a PS should be localized selectivity in the target organism and not in the surrounding tissues or cells, and subsequently excited by low doses of visible light with a suitable wavelength (Figure 3). The stimulated PS transfers energy or electrons to the ground state molecular $\mathrm{O}_{2}$, producing ROS such as a singlet oxygen $\left({ }^{1} \mathrm{O}_{2}\right)$ and ${ }^{\circ} \mathrm{OH}$ that are toxic to target organisms ${ }^{68,69}$ The microbial selectivity of PDT has been described as the result of the different pharmacokinetics of eukaryotes and bacterial cells rather than due to specific molecular targets. ${ }^{70}$ The specificity of PDT is assisted by the condition that ${ }^{1} \mathrm{O}_{2}$, the chief antibacterial type, has a limited half-life and a narrow diffusion dimension at a wavelength of $100 \mathrm{~nm} .^{70}$ The interactions of the motivated PS are by a Type I or a Type II procedure. The Type I procedure is the reaction of an $\bar{e}$ transfer from the PS triplet state, which affects the generation of ROS including $\mathrm{O}_{2}^{-}, \mathrm{OH}^{-}$, and $\mathrm{H}_{2} \mathrm{O}_{2}$. The Type II pathway is the transfer of energy from the PS triplet state to the ground state molecular $\mathrm{O}_{2}$ to form motivated ${ }^{1} \mathrm{O}_{2}$. The bactericidal effects of PDT

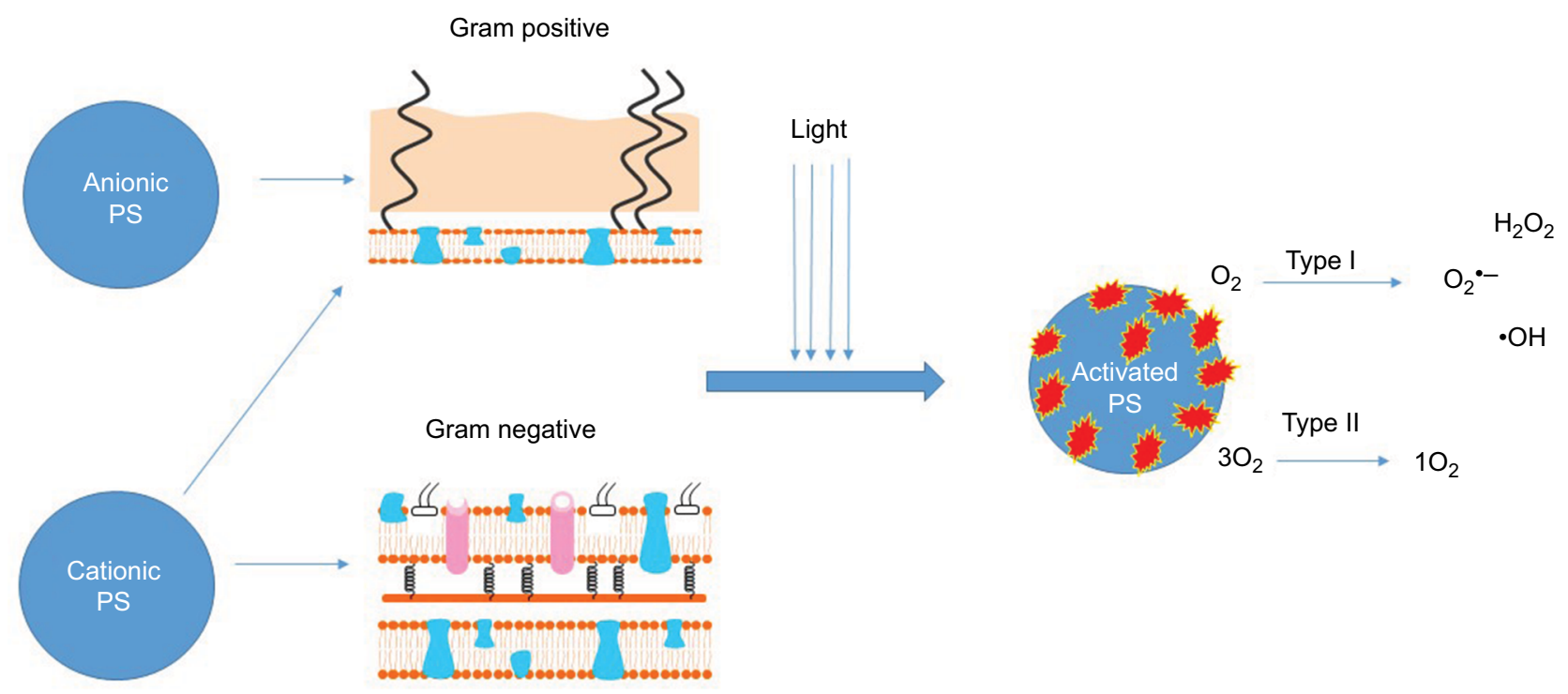

Ground state

Figure 3 Antimicrobial activity of PDT.

Notes: Cationic PS can bind to both Gram-negative and Gram-positive bacteria. Anionic PS generally binds only to Gram-positive bacteria. In the presence of light, PS exits (activated) and induces ROS formation that has antimicrobial effects.

Abbreviations: PDT, photodynamic therapy; PS, photosensitizer; ROS, reactive oxygen species. 
have been observed to be due to the destruction of nucleic acid and/or the cytoplasmic membrane. ${ }^{71}$ PDT also inhibits the toxic effects of endotoxins such as lipopolysaccharides. ${ }^{72}$ Some studies have described PDT as less effective against Gram-negative bacteria due to its lower permeability to certain PS such as curcumin. ${ }^{72,73}$ Phototherapeutically increased spectra have been described by the synergistic effect of mesoporous silica trio-nanohybrids against antibiotic-resistant Gram-negative bacteria. This increased efficiency may be due to the positively charged modified PS and, thus, the increased antimicrobial response through greater affinity to the bacterial cell membrane. ${ }^{72}$ PDT offers considerably more advantages over traditional antibacterial agents. It has antibacterial effects against multidrugresistant isolates, which has an effect significantly quicker than traditional agents. ${ }^{74}$

\section{Hyperbaric oxygen treatment}

Hyperbaric oxygen therapy (HBOT) is a treatment method for soft tissue infections. ${ }^{75}$ HBOT is a systemic method conducted in a pressurized chamber where the patient inhales $100 \% \mathrm{O}_{2}$ for a specified time in which it is delivered by the lung to the whole body. ${ }^{76,77}$ HBOT induces the release of ROS and eliminates the optimum conditions required for obligate and facultative anaerobic bacteria that lack antioxidant defense mechanisms. ${ }^{38}$ The ROS released during HBOT are destructive for DNA and other biologic molecules (Figure 4). ${ }^{78}$ HBOT at a pressure greater than 2 ATA has been shown to have an antibacterial effect against some facultative anaerobic bacteria and aerobic bacteria. ${ }^{79,80}$ HBOT enhances the antibacterial effects of some antibiotics such as imipenem and tobramycin. ${ }^{79,81}$ However, HBOT has been reported to not intensify the antimicrobial effect of distamycin and rifampicin. ${ }^{82}$ The combination therapy of ciprofloxacin and HBOT may be potentially beneficial for the eradication of infections caused by the biofilm forming Pseudomonas aeruginosa..$^{83,84}$ Other than being a direct bactericidal, HBOT enhances the bactericidal mechanisms of impaired host immunity, particularly polymorphonuclear leukocytes, due to wound tissue hypoxia. ${ }^{85}$ HBOT is used as a primary or alternative method for the treatment of infections such as diabetic foot infection, ${ }^{76,86}$ surgical site infections, ${ }^{87}$ gas gangrenes,${ }^{88}$ osteomyelitis, ${ }^{89}$ and necrotizing facilities. ${ }^{87,90}$ In addition to the bactericidal effects, HBOT suppresses the production of clostridia alpha toxin in gas gangrene disease. ${ }^{88}$

\section{Honey therapy}

Honey has been reported to be an effective treatment for wound care due to its antimicrobial effects and healing properties. ${ }^{92}$ The antimicrobial activity of honey is believed to be attributable to its physical properties such as low $\mathrm{pH}$, high osmolality, and the presence of high sugar levels and the antimicrobial components of certain types of honey, such as bee defensin- 1 and hydrogen peroxide, and the induction of $\mathrm{H}_{2} \mathrm{O}_{2}$ generation. ${ }^{91,92}$ There are many types of therapeutic honey in the market (e.g., Paterson's curse, Rosemary, Manuka, Thyme, Revamil, Rewa Rewa, heather honey, Khadi Kraft honey, Multifloral, and Medihoney). ${ }^{93,94}$ Surgihoney RO (SH1) is an approved sterilized honey derived from natural organic honey from different origins. SH1 has been produced

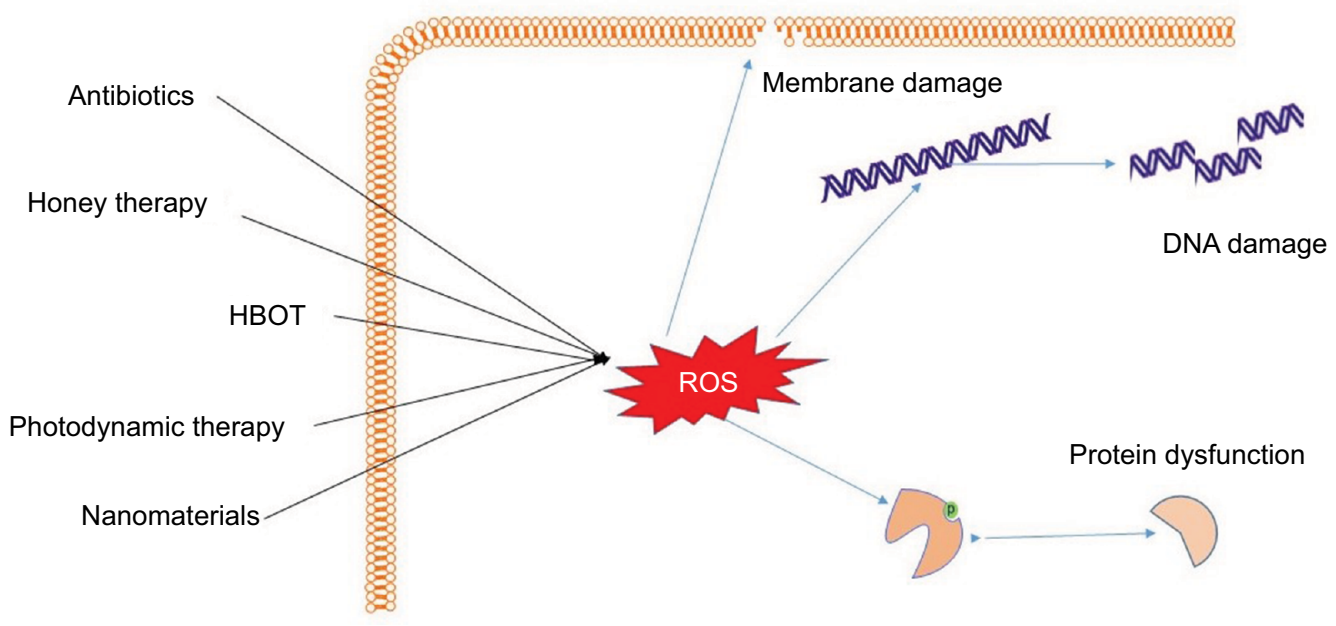

Figure 4 The procedure that inhibits microbial growth by ROS formation and biologic targets.

Notes: In addition to being an alternative bactericidal mechanism of clinically traditional antibiotics, ROS generation is the antimicrobial mechanism of HBOT, medical honey, and photodynamic therapy. The cellular targets for the toxic effects of ROS are DNA and proteins and lipids.

Abbreviations: HBOT, hyperbaric oxygen therapy; ROS, reactive oxygen species. 
as a preventive antimicrobial agent for soft tissue infections. It has been designed by a specific engineering procedure to exert high levels of antimicrobial effects due to ROS generation (Figure 4). Subsequently, ROS induce oxidative stress due to ${ }^{\circ} \mathrm{OH}$ production and inhibit the essential metabolic procedure for bacterial growth. ${ }^{91}$ The main antimicrobial activities of SH1 and two modified prototypes, PT1 and PT2, are due to the ROS hydrogen peroxide. ${ }^{92}$ In addition to $\mathrm{SH} 1$, other formulated prototypes (PT1 and PT2) were designed to increase the generation of $\mathrm{H}_{2} \mathrm{O}_{2}$. This indicates that antimicrobial effects may be applied at an increased potency if desired. ${ }^{91,92}$ This ROS-inducing mechanism provides significant antimicrobial properties that are optimally applicable for the prophylaxis of acute or chronic infections through a honey dressing. ${ }^{92}$ Lower levels of catalase are present in wounds. ${ }^{95}$ It has been reported that catalase levels in healing wounds decrease significantly the first week after the wound is caused and regain their normal activity during the 2 weeks following the injury. ${ }^{96}$ These levels of catalase are, therefore, uncertain to affect the antimicrobial effects induced by exogenously applied SH1 or the two modified prototypes, PT1 and PT2. ${ }^{92}$

\section{Biofilm eradication by ROS-forming procedures}

Biofilms are dense layers of microbial communities attached to different surfaces.$^{97}$ Bacteria in biofilm environments express character differently than planktonic forms, for example, decreased susceptibility to antimicrobial agents. Therefore, biofilms may act as a niche for the recurrence of infections. These infections can remain for months, years, or even a lifetime. It has been estimated that $65 \%$ of the hospitalacquired infections are caused by biofilm forms of microbial growth. ${ }^{98,99}$ Therefore, the development of antibiofilm methods is critical for the management and control of infection, especially in hospital environments. The antibiofilm activity of SH1 has been reported against biofilm-producing bacteria that may cause wound infection. ${ }^{91}$ It has been reported that the reoxygenation of anoxic $P$. aeruginosa biofilm by HBOT increases the bactericidal effects of ciprofloxacin, likely by engaging the aerobic metabolic procedure and resulting in decreased resistance to an antimicrobial agent. Thus, HBOT may be applicable to enhance the effect of antibiotic treatment of infections caused by biofilm-producing organisms. ${ }^{84}$ However, the role of ROS generation as a direct mechanism of antibiofilm activity in these methods needs to be further studied.

\section{Future aspects}

ROS is an effective option for eradicating microbial pathogens. ROS can be induced by a wide variety of procedures. Some of these methods are old and traditional, such as antibiotics, HBOT, and PDT. The increased frequency of antibioticresistant pathogens and the limited options for treatment may encourage the reappearance of attention to the use of these methods. Nanomaterials and engineered medical honey are rather novel methods which can induce ROS formation in microbial cells. Nevertheless, such methods may induce ROS formation in host cells. Therefore, the future development of delivery strategies for increasing the selectivity of ROS for microbial pathogens over the host tissue may make possible the clinical use of ROS. The suppression of host microflora by induced ROS and the economic issues should also be investigated in future studies.

\section{Conclusion}

ROS are molecules effective in inhibiting clinically important microbial pathogens, and they are an attractive option for the treatment of infections. ROS are produced intracellularly as an alternative metabolite due to some biologic pathways; they are also inducible by several artificial exogenous procedures. Certain traditional bactericidal antibiotics and nanomaterials induce ROS as an alternative or a main mechanism of antibacterial effects. HBOT, medical honey, and PDT are other procedures that inhibit microbial growth by forming ROS. These procedures are commonly applied for the treatment or prevention of soft tissue infections, but not for systemic infections. The development of resistance to these methods has not been reported, but selectivity for microbial targets other than host cells and microflora requires further studies. ROS also have a destructive effect on eukaryotes that limits their clinical application as an antimicrobial agent. The clinical application of ROS for infections requires much further research, considering the degenerative circumstances in eukaryotes due to oxidative stress. Identifying the delivery techniques for using ROS with the favorable selectivity of microbial pathogens and without any effects on the host tissue may be potential treatment method for a wide range of infections, especially those caused by drug-resistant organisms.

\section{Disclosure}

The authors report no conflicts of interest in this work.

\section{References}

1. Bush K, Courvalin P, Dantas G, et al. Tackling antibiotic resistance. Nat Rev Microbiol. 2011;9(12):894-896. 
2. Franco BE, Martínez MA, Rodríguez MAS, Wertheimer AI. The determinants of the antibiotic resistance process. Infect Drug Resist. 2009;2:1-10.

3. Payne DJ, Gwynn MN, Holmes DJ, Pompliano DL. Drugs for bad bugs: confronting the challenges of antibacterial discovery. Nat Rev Drug Discov. 2007;6(1):29-40.

4. Dryden M, Cooke J, Salib R, Holding R, Pender SL, Brooks J. Hot topics in reactive oxygen therapy: antimicrobial and immunological mechanisms, safety and clinical applications. J Glob Antimicrob Resist. 2017;8:194-198.

5. Dryden M. Reactive oxygen therapy: a novel therapy in soft tissue infection. Curr. Opin. Infect. Dis. 2017;30(2):143-149.

6. Dunnill C, Patton T, Brennan J, et al. Reactive oxygen species (ROS) and wound healing: the functional role of ROS and emerging ROSmodulating technologies for augmentation of the healing process. Int Wound J. 2017;14(1):89-96.

7. Dryden MS, Cooke J, Salib RJ, et al. Reactive oxygen: a novel antimicrobial mechanism for targeting biofilm-associated infection. J Glob Antimicrob Resist. 2017;8:186-191.

8. Cabiscol E, Tamarit J, Ros J. Oxidative stress in bacteria and protein damage by reactive oxygen species. Int Microbiol. 2000;3(1): 3-8.

9. Imlay JA. The molecular mechanisms and physiological consequences of oxidative stress: lessons from a model bacterium. Nat Rev Microbiol. 2013;11(7):443-454.

10. Lushchak V. Oxidative stress and mechanisms of protection against it in bacteria. Biochemistry. 2001;66(5):476-489.

11. Dwyer DJ, Kohanski MA, Collins JJ. Role of reactive oxygen species in antibiotic action and resistance. Curr Opin Microbiol. 2009;12(5):482-489.

12. Seaver LC, Imlay JA. Are respiratory enzymes the primary sources of intracellular hydrogen peroxide? J Biol Chem. 2004;279(47): 48742-48750.

13. LushchakVI.Adaptive response to oxidative stress: bacteria, fungi, plants and animals. Comp Biochem Physiol C Toxicol Pharmacol. 2011;153(2): 175-190.

14. Sies H. Strategies of antioxidant defense. Eur J Biochem. 1993;215(2): 213-219.

15. Morgan RW, Christman MF, Jacobson FS, Storz G, Ames BN. Hydrogen peroxide-inducible proteins in Salmonella typhimurium overlap with heat shock and other stress proteins. Proc Natl Acad Sci USA. 1986;83(21):8059-8063.

16. Byrne RT, Chen SH, Wood EA, Cabot EL, Cox MM. Escherichia coli genes and pathways involved in surviving extreme exposure to ionizing radiation. J Bacteriol. 2014;196(20):3534-3545.

17. Kohanski MA, Dwyer DJ, Hayete B, Lawrence CA, Collins JJ. A common mechanism of cellular death induced by bactericidal antibiotics. Cell. 2007;130(5):797-810.

18. Albesa I, Becerra MC, Battán PC, Páez PL. Oxidative stress involved in the antibacterial action of different antibiotics. Biochem Biophys Res Commun. 2004;317(2):605-609.

19. Wang D, Zhao L, Ma H, Zhang H, Guo L-H. Quantitative analysis of reactive oxygen species photogenerated on metal oxide nanoparticles and their bacteria toxicity: the role of superoxide radicals. Environ Sci Technol. 2017;51(17):10137-10145.

20. Kumar A, Pandey AK, Singh SS, Shanker R, Dhawan A. Engineered $\mathrm{ZnO}$ and $\mathrm{TiO} 2$ nanoparticles induce oxidative stress and DNA damage leading to reduced viability of Escherichia coli. Free Radic Biol Med. 2011;51(10):1872-1881.

21. Joshi SG, Cooper M, Yost A, et al. Nonthermal dielectric-barrier discharge plasma-induced inactivation involves oxidative DNA damage and membrane lipid peroxidation in Escherichia coli. Antimicrob Agents Chemother. 2011;55(3):1053-1062.

22. Cadet J, Douki T, Gasparutto D, Ravanat J-L. Oxidative damage to DNA: formation, measurement and biochemical features. Mutat Res. 2003;531(1):5-23.
23. Beckman KB, Ames BN. Oxidative decay of DNA. J Biol Chem. 1997;272(32):19633-19636.

24. Henle ES, Han Z, Tang N, Rai P, Luo Y, Linn S. Sequence-specific DNA cleavage by $\mathrm{Fe}^{2+}$-mediated fenton reactions has possible biological implications. J Biol Chem. 1999;274(2):962-971.

25. Rai P, Wemmer DE, Linn S. Preferential binding and structural distortion by $\mathrm{Fe}^{2+}$ at RGGG-containing DNA sequences correlates with enhanced oxidative cleavage at such sequences. Nucleic Acids Res. 2005;33(2):497-510.

26. Ayala A, Muñoz MF, Argüelles S. Lipid peroxidation: production, metabolism, and signaling mechanisms of malondialdehyde and 4-hydroxy-2-nonenal. Oxid Med Cell Longev. 2014; 2014:360438.

27. Avery SV. Molecular targets of oxidative stress. Biochem J. 2011;434(2): 201-210.

28. Fang FC. Antimicrobial reactive oxygen and nitrogen species: concepts and controversies. Nat Rev Microbiol. 2004;2(10):820-832.

29. Birben E, Sahiner UM, Sackesen C, Erzurum S, Kalayci O. Oxidative stress and antioxidant defense. World Allergy Organ J. 2012;5(1):9-19.

30. Tamarit J, Cabiscol E, Ros J. Identification of the major oxidatively damaged proteins in Escherichia coli cells exposed to oxidative stress. J Biol Chem. 1998;273(5):3027-3032.

31. Vatansever F, de Melo WC, Avci P, et al. Antimicrobial strategies centered around reactive oxygen species-bactericidal antibiotics, photodynamic therapy, and beyond. FEMS Microbiol Rev. 2013;37(6):955-989.

32. Semchyshyn H, Bagnyukova T, Storey K, Lushchak V. Hydrogen peroxide increases the activities of soxRS regulon enzymes and the levels of oxidized proteins and lipids in Escherichia coli. Cell Biol Int. 2005;29(11):898-902.

33. Carlyon JA, Latif DA, Pypaert M, Lacy P, Fikrig E. Anaplasma phagocytophilum utilizes multiple host evasion mechanisms to thwart NADPH oxidase-mediated killing during neutrophil infection. Infect Immun. 2004;72(8):4772-4783.

34. Woldehiwet $Z$. Immune evasion and immunosuppression by Anaplasma phagocytophilum, the causative agent of tick-borne fever of ruminants and human granulocytic anaplasmosis. Vet J. 2008;175(1):37-44.

35. Siemsen DW, Kirpotina LN, Jutila MA, Quinn MT. Inhibition of the human neutrophil NADPH oxidase by Coxiella burnetii. Microbes Infect. 2009;11(6):671-679.

36. Zhang W, Li Y, Niu J, Chen Y. Photogeneration of reactive oxygen species on uncoated silver, gold, nickel, and silicon nanoparticles and their antibacterial effects. Langmuir. 2013;29(15):4647-4651.

37. Bhattacharya G, Dey D, Das S, Banerjee A. Exposure to sub-inhibitory concentrations of gentamicin, ciprofloxacin and cefotaxime induces multidrug resistance and reactive oxygen species generation in methicillin-sensitive Staphylococcus aureus. J Med Microbiol. 2017;66(6):762-769.

38. Çimşit M, Uzun G, Yıldız Ş. Hyperbaric oxygen therapy as an antiinfective agent. Expert Rev Anti Infect Ther. 2009;7(8):1017-1026.

39. Seaver LC, Imlay JA. Hydrogen peroxide fluxes and compartmentalization inside growing Escherichia coli. J Bacteriol. 2001;183(24):7182-7189.

40. Amabile-Cuevas CF, Demple B. Molecular characterization of the soxRS genes of Escherichia coli: two genes control a superoxide stress regulon. Nucleic Acids Res. 1991;19(16):4479-4484.

41. Koo MS, Lee JH, Rah SY, et al. A reducing system of the superoxide sensor SoxR in Escherichia coli. EMBO J. 2003;22(11):2614-2622.

42. Pomposiello PJ, Demple B. Global adjustment of microbial physiology during free radical stress. Adv Microb Physiol. 2002;46:319-341.

43. Dizaj SM, Lotfipour F, Barzegar-Jalali M, Zarrintan M-H, Adibkia K. Box-Behnken experimental design for preparation and optimization of ciprofloxacin hydrochloride-loaded $\mathrm{CaCO}_{3}$ nanoparticles. J Drug Deliv Sci Technol. 2015;29:125-131.

44. Dizaj SM, Lotfipour F, Barzegar-Jalali M, Zarrintan M-H, Adibkia K. Physicochemical characterization and antimicrobial evaluation of gentamicin-loaded $\mathrm{CaCO}_{3}$ nanoparticles prepared via microemulsion method. J Drug Deliv Sci Technol. 2016;35:16-23. 
45. Mohammadi G, Valizadeh H, Barzegar-Jalali M, et al. Development of azithromycin-PLGA nanoparticles: physicochemical characterization and antibacterial effect against Salmonella typhi. Colloids Surf B Biointerfaces. 2010;80(1):34-39.

46. Mohammadi G, Nokhodchi A, Barzegar-Jalali M, et al. Physicochemical and anti-bacterial performance characterization of clarithromycin nanoparticles as colloidal drug delivery system. Colloids Surf B Biointerfaces. 2011;88(1):39-44.

47. Dizaj SM, Lotfipour F, Barzegar-Jalali M, Zarrintan MH, Adibkia K. Antimicrobial activity of the metals and metal oxide nanoparticles. Mater Sci Eng C Mater Biol Appl. 2014;44:278-284.

48 Maness P-C, Smolinski S, Blake DM, Huang Z, Wolfrum EJ, Jacoby WA. Bactericidal activity of photocatalytic $\mathrm{TiO} 2$ reaction: toward an understanding of its killing mechanism. Appl Environ Microbiol. 1999;65(9):4094-4098.

49. Azam A, Ahmed AS, Oves M, Khan MS, Habib SS, Memic A. Antimicrobial activity of metal oxide nanoparticles against Gram-positive and Gram-negative bacteria: a comparative study. Int J Nanomedicine. 2012;7:6003-6009.

50. Fayaz AM, Balaji K, Girilal M, Yadav R, Kalaichelvan PT, Venketesan R. Biogenic synthesis of silver nanoparticles and their synergistic effect with antibiotics: a study against gram-positive and gram-negative bacteria. Nanomedicine. 2010;6(1):103-109.

51. Li Y, Zhang W, Niu J, Chen Y. Mechanism of photogenerated reactive oxygen species and correlation with the antibacterial properties of engineered metal-oxide nanoparticles. ACS Nano. 2012;6(6):5164-5173.

52. Long TC, Saleh N, Tilton RD, Lowry GV, Veronesi B. Titanium dioxide (P25) produces reactive oxygen species in immortalized brain microglia (BV2): implications for nanoparticle neurotoxicity. Environ Sci Technol. 2006;40(14):4346-4352.

53. Kankala RK, Liu C-G, Chen A-Z, et al. Overcoming multidrug resistance through the synergistic effects of hierarchical pH-sensitive, ROSgenerating nanoreactors. ACS Biomater Sci Eng. 2017;3(10):2431-2442.

54. Kankala RK, Tsai P-Y, Kuthati Y, Wei P-R, Liu C-L, Lee C-H. Overcoming multidrug resistance through co-delivery of ROSgenerating nano-machinery in cancer therapeutics. J Mater Chem B. 2017;5(7):1507-1517.

55. Kankala RK, Kuthati Y, Liu C-L, Lee C-H. Hierarchical coated metal hydroxide nanoconstructs as potential controlled release carriers of photosensitizer for skin melanoma. RSC Adv. 2015;5(53):42666-42680.

56. Fu PP, Xia Q, Hwang H-M, Ray PC, Yu H. Mechanisms of nanotoxicity: generation of reactive oxygen species. J Food Drug Anal. 2014;22(1):64-75.

57. Ivask A, Bondarenko O, Jepihhina N, Kahru A. Profiling of the reactive oxygen species-related ecotoxicity of $\mathrm{CuO}, \mathrm{ZnO}, \mathrm{TiO}_{2}$, silver and fullerene nanoparticles using a set of recombinant luminescent Escherichia coli strains: differentiating the impact of particles and solubilised metals. Anal Bioanal Chem. 2010;398(2):701-716.

58. He W, Wu H, Wamer WG, et al. Unraveling the enhanced photocatalytic activity and phototoxicity of $\mathrm{ZnO} /$ metal hybrid nanostructures from generation of reactive oxygen species and charge carriers. ACS Appl Mater Interfaces. 2014;6(17):15527-15535.

59. Brunet L, Lyon DY, Hotze EM, Alvarez PJ, Wiesner MR. Comparative photoactivity and antibacterial properties of $\mathrm{C} 60$ fullerenes and titanium dioxide nanoparticles. Environ Sci Technol. 2009;43(12):4355-4360.

60. Kalghatgi S, Spina CS, Costello JC, et al. Bactericidal antibiotics induce mitochondrial dysfunction and oxidative damage in mammalian cells. Sci Transl Med. 2013;5(192):192ra185.

61. Becerra M, Albesa I. Oxidative stress induced by ciprofloxacin in Staphylococcus aureus. Biochem Biophys Res Commun. 2002;297(4): 1003-1007.

62. Dridi B, Lupien A, Bergeron MG, Leprohon P, Ouellette M. Differences in antibiotic-induced oxidative stress responses between laboratory and clinical isolates of Streptococcus pneumoniae. Antimicrob Agents Chemother. 2015;59(9):5420-5426.
63. Kohanski MA, DePristo MA, Collins JJ. Sublethal antibiotic treatment leads to multidrug resistance via radical-induced mutagenesis. $\mathrm{Mol}$ Cell. 2010;37(3):311-320.

64. Wang X, Zhao X. Contribution of oxidative damage to antimicrobial lethality. Antimicrob Agents Chemother. 2009;53(4):1395-1402.

65. Dwyer DJ, Belenky PA, Yang JH, et al. Antibiotics induce redox-related physiological alterations as part of their lethality. Proc Natl Acad Sci USA. 2014;111(20):2100-2109.

66. Kharkwal GB, Sharma SK, Huang YY, Dai T, Hamblin MR. Photodynamic therapy for infections: clinical applications. Lasers Surg Med. 2011;43(7):755-767.

67. Donnelly RF, McCarron PA, Tunney MM, Woolfson AD. Potential of photodynamic therapy in treatment of fungal infections of the mouth. Design and characterisation of a mucoadhesive patch containing toluidine blue O. J Photochem Photobiol B. 2007;86(1): 59-69.

68. Maisch T. Anti-microbial photodynamic therapy: useful in the future? Lasers Med Sci. 2007;22(2):83-91.

69. Dai T, Huang Y-Y, Hamblin MR. Photodynamic therapy for localized infections-state of the art. Photodiagnosis Photodyn Ther. 2009;6(3):170-188.

70. O'Riordan K, Akilov OE, Hasan T. The potential for photodynamic therapy in the treatment of localized infections. Photodiagnosis Photodyn Ther. 2005;2(4):247-262.

71. Demidova T, Hamblin M. Photodynamic therapy targeted to pathogens. Int J Immunopathol Pharmacol. 2004;17(3):245-254.

72. Kuthati Y, Kankala RK, Busa P, et al. Phototherapeutic spectrum expansion through synergistic effect of mesoporous silica trio-nanohybrids against antibiotic-resistant gram-negative bacterium. J Photochem Photobiol B. 2017;169:124-133.

73. F Sperandio F, Huang Y-Y, R Hamblin M. Antimicrobial photodynamic therapy to kill Gram-negative bacteria. Recent Pat Antiinfect Drug Discov. 2013;8(2):108-120.

74. Dai T, Tegos GP, Zhiyentayev T, Mylonakis E, Hamblin MR. Photodynamic therapy for methicillin-resistant Staphylococcus aureus infection in a mouse skin abrasion model. Lasers Surg Med. 2010;42(1): $38-44$.

75. Goerger E, Honnorat E, Savini H, et al. Anti-infective therapy without antimicrobials: apparent successful treatment of multidrug resistant osteomyelitis with hyperbaric oxygen therapy. IDCases. 2016;6: 60-64.

76. Duzgun AP, Satır HZ, Ozozan O, Saylam B, Kulah B, Coskun F. Effect of hyperbaric oxygen therapy on healing of diabetic foot ulcers. J Foot Ankle Surg. 2008;47(6):515-519.

77. Kaide CG, Khandelwal S. Hyperbaric oxygen: applications in infectious disease. Emerg Med Clin North Am. 2008;26(2):571-595.

78. Gill A, Bell CN. Hyperbaric oxygen: its uses, mechanisms of action and outcomes. QJM. 2004;97(7):385-395.

79. Lima FL, Joazeiro PP, Lancellotti M, et al. Effects of hyperbaric oxygen on Pseudomonas aeruginosa susceptibility to imipenem and macrophages. Future Microbiol. 2015;10(2):179-189.

80. Bumah VV, Whelan HT, Masson-Meyers DS, Quirk B, Buchmann E, Enwemeka CS. The bactericidal effect of 470-nm light and hyperbaric oxygen on methicillin-resistant Staphylococcus aureus (MRSA) Lasers Med Sci. 2015;30(3):1153-1159.

81. Lerche C, Christophersen L, Kolpen M, et al. Hyperbaric oxygen therapy augments tobramycin efficacy in experimental Staphylococcus aureus endocarditis. Int J Antimicrob Agents. 2017;50(3): 406-412.

82. Jørgensen NP, Hansen K, Andreasen CM, et al. Hyperbaric oxygen therapy is ineffective as an adjuvant to daptomycin with rifampicin treatment in a murine model of Staphylococcus aureus in implantassociated osteomyelitis. Microorganisms. 2017;5(2):21.

83. Kolpen M, Lerche CJ, Kragh KN, et al. Hyperbaric oxygen sensitizes anoxic Pseudomonas aeruginosa biofilm to ciprofloxacin. Antimicrob Agents Chemother. 2017;61(11):e01024-17. 
84. Kolpen M, Mousavi N, Sams T, et al. Reinforcement of the bactericidal effect of ciprofloxacin on Pseudomonas aeruginosa biofilm by hyperbaric oxygen treatment. Int J Antimicrob Agents. 2016;47(2):163-167.

85. Hopf HW, Holm J. Hyperoxia and infection. Best Pract Res Clin Anaesthesiol. 2008;22(3):553-569.

86. Chen CE, Ko JY, Fong CY, Juhn R-J. Treatment of diabetic foot infection with hyperbaric oxygen therapy. Foot Ankle Surg. 2010;16(2):91-95.

87. Barili F, Polvani G, Topkara VK, et al. Role of hyperbaric oxygen therapy in the treatment of postoperative organ/space sternal surgical site infections. World J Surg. 2007;31(8):1702-1706.

88. Korhonen K, Klossner J, Hirn M, Niinikoski J. Management of clostridial gas gangrene and the role of hyperbaric oxygen. Ann Chir Gynaecol. 1999;88(2):139-142.

89. Ahmed R, Severson MA III, Traynelis VC. Role of hyperbaric oxygen therapy in the treatment of bacterial spinal osteomyelitis. J Neurosurg Spine. 2009;10(1):16-20.

90. Wilkinson D, Doolette D. Hyperbaric oxygen treatment and survival from necrotizing soft tissue infection. Arch Surg. 2004;139(12):1339-1345.

91. Halstead F, Webber M, Rauf M, Burt R, Dryden M, Oppenheim B. In vitro activity of an engineered honey, medical-grade honeys, and antimicrobial wound dressings against biofilm-producing clinical bacterial isolates. J Wound Care. 2016;25(2):93-102.
92. Cooke J, Dryden M, Patton T, Brennan J, Barrett J. The antimicrobial activity of prototype modified honeys that generate reactive oxygen species (ROS) hydrogen peroxide. BMC Res Notes. 2015;8(1):20.

93. Mullai V, Menon T. Bactericidal activity of different types of honey against clinical and environmental isolates of Pseudomonas aeruginosa. J Altern Complement Med. 2007;13(4):439-442.

94. Wilkinson JM, Cavanagh HM. Antibacterial activity of 13 honeys against Escherichia coli and Pseudomonas aeruginosa. J Med Food. 2005;8(1):100-103.

95. Goth L. A simple method for determination of serum catalase activity and revision of reference range. Clin Chim Acta. 1991;196(2-3): 143-151.

96. Wattamwar PP, Dziubla TD. Modulation of the wound healing response through oxidation active materials. In: Engineering Biomaterials for Regenerative Medicine: New York, NY: Springer; 2012:161-192.

97. Ghotaslou R, Salahi B. Effects of oxygen on in vitro biofilm formation and antimicrobial resistance of Pseudomonas aeruginosae. Pharm Sci. 2013;19(3):96-99.

98. Mah T-FC, O'Toole GA. Mechanisms of biofilm resistance to antimicrobial agents. Trends Microbiol. 2001;9(1):34-39.

99. Stewart PS, Costerton JW. Antibiotic resistance of bacteria in biofilms. Lancet. 2001;358(9276):135-138.
Infection and Drug Resistance

\section{Publish your work in this journal}

Infection and Drug Resistance is an international, peer-reviewed openaccess journal that focuses on the optimal treatment of infection (bacterial, fungal and viral) and the development and institution of preventive strategies to minimize the development and spread of resistance. The journal is specifically concerned with the epidemiology of antibiotic

\section{Dovepress}

resistance and the mechanisms of resistance development and diffusion in both hospitals and the community. The manuscript management system is completely online and includes a very quick and fair peerreview system, which is all easy to use. Visit http://www.dovepress.com/ testimonials.php to read real quotes from published authors. 